\title{
Analysis of Load-Type Crack Formation Mechanism of Semi-Rigid Based Asphalt Pavement
}

\author{
Zheng Chuanfeng ${ }^{1,2}$, Yang Xue ${ }^{1}$, Ma Zhuang ${ }^{1}$, Yang Chun ${ }^{1}$ \\ 1. College of Construction Engineering, Jilin University, Changchun 130026, China \\ 2.College of Traffic, Jilin University, Changchun 130022, China
}

\begin{abstract}
KEYWORD: road engineering, semi-rigid based asphalt pavement, strain field, strain level ABSTRACT: This article investigates the load-type crack formation mechanism of semi-rigid based asphalt pavement. The XYJ-2 concrete strain sensors are used to detect the strain field created by standard loads acting on the pavement structure. The ultimate bending tensile strains of the materials are tested through indoor experiments. Cracking positions are pre-estimated using strain level. The results show the existence of pressure, weak-pull and strong-pull areas in the pavement structure. Original cracking points appear at the bottom of the base and the subbase courses where the strain levels are high. The fundamental cause of load-type cracks in semi-rigid based asphalt pavement is that the structure of the semi-rigid based asphalt pavement does not match the distribution of the strain field in the pavement structure..
\end{abstract}

\section{INSTRUCTION}

Semi-rigid based asphalt pavements are built more extensively in China, and their applications are expanding annually in other countries around the world[1]. This pavement structure possesses a larger load-bearing capacity and is subjected to less pavement-rutting damage because of the greater stiffness of the semi-rigid base course of semi-rigid based asphalt pavement . in recent years, surveys have shown that frequent occurrence of early cracking diseases restricts severely the application of semi-rigid based asphalt pavements[2].

Full-scale experiment conducted to detect pavement structural strain field is an effective way at finding the strain distribution law of structural courses[3]. According to the strain distribution law of courses, material properties, such as material thickness, material modulus and so on, have to be chosen properly. The key to the pavement structural strain field test is to choose the proper strainsensor devices, try to increase the survival percentage of strain sensors and ensure the accuracy of the test[4].

The current study adopts the method in which XYJ-2 concrete strain sensors are embedded into high-grade semi-rigid based asphalt pavement structural courses in advance, conducts full-scale test for the pavement structural strain field and examines the load-type crack formation mechanism of semi-rigid based asphalt pavement based on measurement results.

\section{STRAIN FIELD TEST OF THE PAVEMENT STRUCTURE}

\section{Test section pavement structure and strain sensor layout}

The working principle of XYJ-2 strain sensors is that a steel string is stretched between two flanges at the two ends of the strain sensor, the resulting material deformation will make the flanges undergo relative motions. The flange displacement causes changes in the stress of the steel string. When subjected to shock by an electromagnetic coil, the steel string vibrates, and in return, the vibrating string lets the electromagnetic coil generate one frequency signal. This signal will be transported to the vibrating string frequency detector, which will show the corresponding data of the frequency signal. The technical parameters of the XYJ-2 strain sensors are shown in Table1. 
Table1. Main technical parameters of the XYJ-2 strain sensors.

\begin{tabular}{lllll}
\hline $\begin{array}{l}\text { Working } \\
\text { Length } \\
\mathrm{mm})\end{array}$ & $\begin{array}{l}\text { Flange Diame- } \\
\text { ter } \\
(\mathrm{mm})\end{array}$ & $\begin{array}{l}\text { Maximum } \\
\text { Strain }\left(10^{-6}\right)\end{array}$ & $\begin{array}{l}\text { Resolution } \\
\text { Ration }\end{array}$ & $\begin{array}{l}\text { Comprehensive } \\
\text { Error }\end{array}$ \\
\hline 150 & 19.5 & 3000 & $<0.2 \% \mathrm{~F} . \mathrm{S}$ & $<2.0 \% \mathrm{~F} . \mathrm{S}$
\end{tabular}

The materials used in the pavement structural courses at the three different test sections are the same. The pavement structure consists of the following parts: $4 \mathrm{~cm}$-thick top surface course of SMA-13 asphalt mixture, $5 \mathrm{~cm}$-thick middle surface course of AC-16 asphalt mixture, $6 \mathrm{~cm}$-thick bottom surface course of AC-20 asphalt mixture, $30 \mathrm{~cm}$-thick base course of cement-stabilised macadam, $20 \mathrm{~cm}$-thick sub-base course of lime and fly ash-stabilised macadam. The three test sections have obviously different subgrades: Section I: The material is clayey soil, and the compressive modulus is 36Mpa. Section II: The material is soil sand, and the compressive modulus is 66Mpa. Section III: The material is change gravel filling, and the compressive modulus is $120 \mathrm{Mpa}$.

The manner on how the sensors are buried has a large influence on the result of the strain test [5]. During the study, the burying of the strain sensors involves three main steps: pre-positioning, preburying and burial. The sensor-burial positions include the bottoms of both the top surface, the middle course and the bottom surface courses, as well as the bottoms of both the base and the subbase courses. The sensors are laid in two rows, and a $30 \mathrm{~cm}$-space exists between the rows (as shown in Fig. 1). To obtain the strain field law, the sensors are laid at three different test sections which have different subgrade, and parallel trials are conducted in every section.

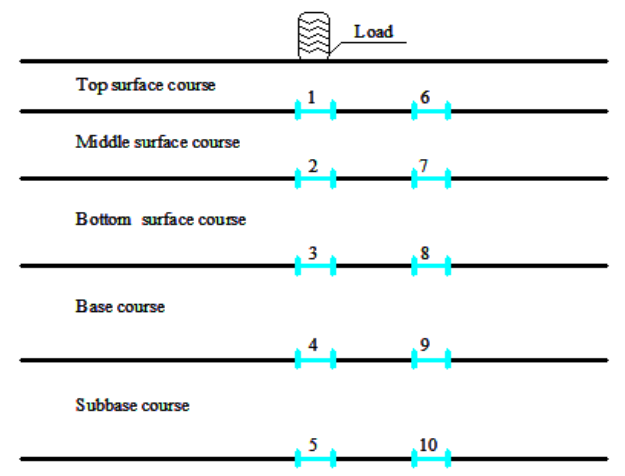

Fig.1. Vertical layout of the strain sensors (Nos.1-10 represent strain sensors)

\section{Strain field test result}

The strain field of the semi-rigid based asphalt pavement is obtained by mean processing of the test data from the three test sections, as shown in Table2.

\begin{tabular}{|c|c|c|c|}
\hline \multirow{2}{*}{$\begin{array}{r}\text { Strain sensor } \\
\mathrm{Sec}\end{array}$} & \multicolumn{3}{|c|}{ Mean strains of each section $(\mu \varepsilon)$} \\
\hline & on I & Section II & Section III \\
\hline 1 & -685.7 & -718.7 & -929.7 \\
\hline 2 & -496.5 & -515.5 & -716.2 \\
\hline 3 & 179.7 & 119.2 & 82.5 \\
\hline 4 & 400.2 & 308.2 & 212.5 \\
\hline 5 & 428.6 & 422.7 & 278.6 \\
\hline 6 & 115.7 & 78.2 & 81.3 \\
\hline 7 & 110.8 & 71.1 & 85.7 \\
\hline 8 & 320.7 & 259.2 & 198.8 \\
\hline 9 & 387.6 & 378.1 & 221.3 \\
\hline 10 & 411.4 & 410.6 & 243.5 \\
\hline
\end{tabular}


The area under compressive strain is defined as the pressure area, the area where the strain is below $200 \mu \varepsilon$ is defined as the weak-pull area and the area where the strain is over $200 \mu \varepsilon$ is defined as the strong-pull area. The top surface, the middle surface and the top of the bottom surface courses are within the pressure area. The bottom of the bottom surface and the top of the base courses are in the weak-pull area. The bottom of the base and the entire sub-base courses are in the strong-pull area.

\section{ULTIMATE TENSILE STRAIN TEST OF THE PAVEMENT MATERIAL}

\section{Test method}

Based on China's current Standard Test Methods of Bitumen and Bituminous Mixtures for Highway Engineering (JTJ052-2000), the UTM-100 multi-function testing machine is adopted to determine the mechanical properties when the asphalt mixture is under load. The three-point loading method is adopted for the asphalt mixture bending test. Based on the National institute of Standards of the People's Republic of China Standard for Test Method of Mechanical Properties on Ordinary Concrete(GB/T5008122002). The beam specimens of the cement-stabilised and the lime and fly ashstabilised macadams are used in the bending test. Three pieces of strain gauges are attached to the bottom of each specimen, parallel to the axist; the layout of the strain gauges is shown in Fig. 2.

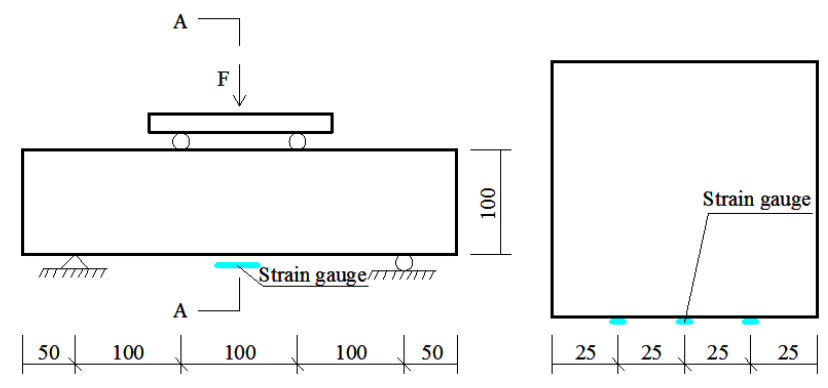

Fig.2. Layout of the strain gauges.

\section{Ultimate tensile strain test results}

The results of the ultimate bending tensile strain test of the different structural courses are shown in Figs. 3.

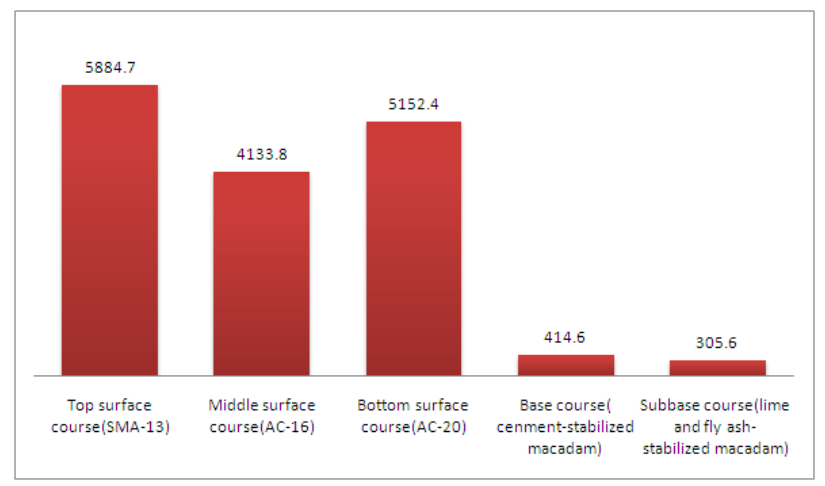

Fig.3. Comparison of the ultimate bending tensile strain of each pavement structural course ( $\mu z)$

\section{ESTIMATION OF ORIGINAL CRACKING COURSES}

Strain level is defined as the ratio of the actual strain value in the structural course to the ultimate strain value of the material. According to the relationship between the material fatigue life and the strain level [Eq. (1)], the strain level is inversely proportional to the material fatigue life .

$$
\mathrm{N}=\mathrm{C}\left(\frac{1}{\varepsilon}\right)^{m}
$$


where:

$\mathrm{N}$-loading times until the specimen's fatigue

$\varepsilon$ - constant maximum strain margin exerted on the specimen

$C, m$-constants related to the material properties

The strain level of each structural course can be calculated (as shown in Figs. 4-6).

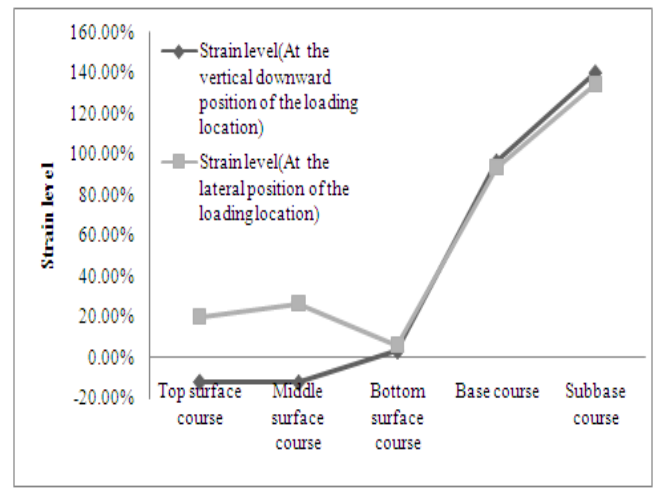

Fig.4. Comparison of the strain levels of courses in test section I (subgrade compressive modulus $=36 \mathrm{MPa}$ )

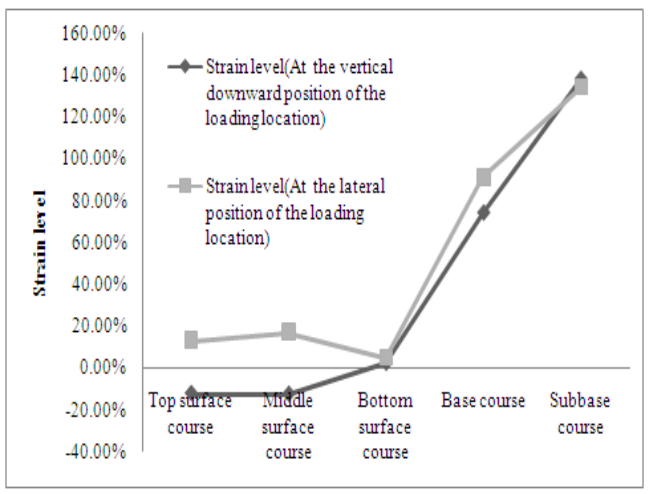

Fig.5. Comparison of the strain levels of courses in test section II (subgrade compressive modulus $=66 \mathrm{MPa}$ )

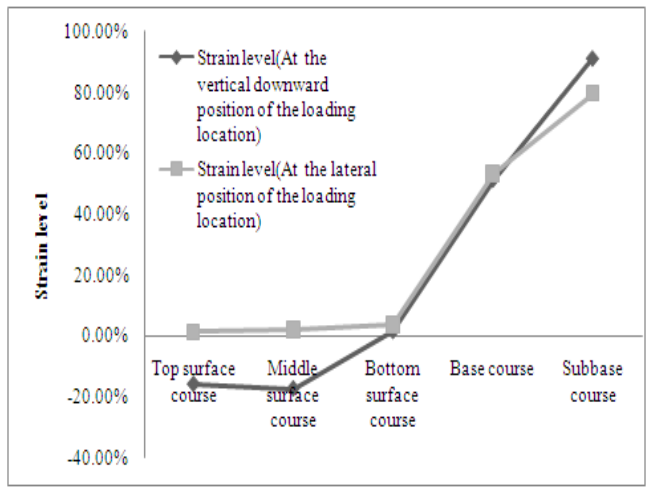

Fig.6 Comparison of the strain levels of courses in test section III (subgrade compressive modulus $=120 \mathrm{MPa}$ )

According to the analysed result of the strain level, the strain level increases from the top surface course to the subbase course. 
Portions of both the top and middle surface courses of the semi-rigid based asphalt pavement are completely under pressure. The SMA-13 and the AC-16 asphalt mixtures are under a pressure strain, and the strain level is negative. The original cracking courses basically cannot occur in the top and middle surface courses.

Part of the bottom surface course of the AC-20 asphalt is under tension, but the strain level at the tensile part is very low. The strain level at the position vertically down the loading location is not over $4 \%$, and the strain level at the lateral position of the loading location is not over $7 \%$. Under this strain-level condition, the fatigue life of the asphalt mixture is considerably longer than the design life, therefore the bottom surface course cannot also be the location of the original cracking course. Higher strain level appears at the base course. With a lower subgrade compressive modulus, the tensile strain generated by vehicle loads is close to the ultimate bending tensile strain. After a certain number of vehicle loads act on the pavement, the original cracking position will occur at the base course. With higher subgrade compressive modulus, the base material has longer fatigue life and cannot crack within a short time.

For the semi-rigid based asphalt pavement, the subbase course directly touching the subgrade course has a large deformation. With lower subgrade compressive modulus, as shown in the example of test section I, the top of the subgrade experiences larger deformation, and the bottom of the subbase experiences larger strain. The strain level vertically down the loading location is $140.2 \%$, and the strain level at the lateral position of the loading location is $134.6 \%$. Hence, the original cracking positions occur at the subbase course. With higher subgrade compressive modulus, as shown in the example of test section III, the strain level generated by vehicle loads at the subbase course is close to the ultimate bending tensile strain of the lime and fly ash-stabilised macadam subbase course, therefore, the original cracking points are likely to appear here.

Combining the analyses of the strain level of each course of the semi-rigid based asphalt pavement, the original cracking points appear at the base and the subbase courses. When the subgrade compressive modulus is lower, the subgrade vertical deformation is larger, thus, the bending deformation of the structural course is larger. Under this condition, the original cracking points will appear at both the base and the subbase courses.

\section{CONCLUSIONS}

This study have used strain sensors to measure the strain field of typical semi-rigid based road structures, examined the strain features of each structural course, determined the strain level of each course and pre-estimated the original cracking positions of the semi-rigid based pavement structure. The conclusions are enumerated as follows:

(1)Portions of the top surface and the middle surface courses of the semi-rigid based asphalt pavement directly below the loading location are completely under pressure, original cracking positions basically cannot occur at either the top surface or the middle surface courses of the semi-rigid based asphalt pavement.

(2)Some parts of the bottom surface course of the asphalt mixture are under tension. However, the strain level of the tensile parts is very low, therefore the mixture is less likely to crack.

(3)The strain level of the base course is closely related to the subgrade compressive resilient modulus. Under the condition of lower subgrade compressive modulus, the base material will generate the original cracks. With the increase in the subgrade compressive modulus, the base material is not likely to crack within a short time.

(4)When the subgrade compressive modulus is low, the original cracking points appear at the subbase course. With increasing subgrade compressive modulus, the original cracks are more likely to appear at the subbase course. 


\section{REFERENCES}

[1] Zhao Yongli, Huang Xiaoming. Design method and performance for large stone porous asphalt mixture. Journal of Wuhan university of technology-materials science 2010; 25(5): 871-876.

[2] Zhi Suo, Gun Wong-wing, Hui Luo xiao. Evaluation of fatigue crack behavior in asphalt concrete pavements with different polymer modifiers. Construction and building materials 2011;

27(1):117-125.

[3] Haritonovs Viktors. Permanent strain development dynamics for asphalt pavement materials. Baltic journal of road and bridge engineering 2011; 6(2):135-143

[4] Seo Youngguk. A full scale in situ evaluation of strain characteristics at highway flexible pavement sections. Journal of testing and evaluation 2010; 38(4):390-399.

[5] Zou Hongbo, Liang Dakai, Zeng Jie. Dynamic strain measurement using two wavelengthmatched fiber Bragg grating sensors interrogated by a cascaded long-period fiber grating. Optics and lasers in engineering $2011 ; 50(2)$

:199-203 